Arquimedes Pessoni

Universidade Municipal

de São Caetano do Sul, São Caetano do Sul, SP, Brasil.

Rita de Cássia

Donato dos Santos

Universidade Municipal de São Caetano do Sul, São Caetano do Sul, SP, Brasil.

\section{A presença social dos Deputados Federais do Grande ABC no Facebook}

\author{
The social presence of the \\ Deputies from Grande \\ ABC in Facebook
}

\author{
La presencia social de los \\ diputados Federales del \\ Grande ABC en Facebook
}




\section{RESUMO}

Este artigo propõe reflexão a respeito da comunicação política na cibercultura, discorrendo sobre o uso do Facebook nas campanhas eleitorais dos deputados federais do Grande ABC em 2014. Guiada por entrevistas abertas e análise de conteúdo qualitativa das fanpages desses personagens, esta pesquisa buscou identificar a presença social dos parlamentares a partir das categorias instituídas por Rourke et al. (2001): afetividade, coesão e interatividade. Optou-se pela semana construída para analisar uma amostragem dos posts veiculados no período eleitoral, com o suporte do software Atlas TI. Os resultados refletem a presença social coesiva, em ambos os casos, pautada no fortalecimento de grupos políticos e na relação de proximidade com as comunidades locais.

Palavras-chave: Comunicação política. Presença social. Facebook. Grande ABC.

\section{ABSTRACT}

This article talks about political communication in cyberculture, arguing in which ways the representatives for the government from Grande ABC used their Facebook accounts in the election of 2014. Guided by open interviews and qualitative analysis of the material of the fanpages of these characters, it was sought to identify the social presence of the parliamentarians from the categories instituted by Rourke ef al. (2001): affectivity, cohesion and interactivity. This analysis follows the concept of the constructed week to evaluate a loyal sample of the posts during the election process, with the support of Atlas IT software. Results reflect the cohesive present socially, in both cases, based on the strengthening of political groups and the proximity with local communities.

Keywords: Political communication. Social presence. Facebook. Grande ABC.

\section{RESUMEN}

El artículo trata sobre la comunicación política en la cibercultura, argumentando de que manera los diputados del Grande ABC utilizaron sus cuentas de Facebook en la elección de 2014. Guiado por entrevistas abiertas y análisis cualitativos del material de las páginas de estos personajes, se buscó identificar la presencia social de estos parlamentarios de las categorías instituidas por Rourke et al. (2001): afectividad, cohesión e interactividad. Estos análisis siguen el concepto de la semana construida para evaluar una muestra leal de los mensajes durante el proceso electoral, con el apoyo del software Atlas de TI. Los resultados reflejan la presencia social cohesiva, en ambos casos, basado en el fortalecimiento de los grupos políticos y la proximidad con las comunidades locales.

Palabras clave: Comunicación política. Presencia social. Facebook. Grande ABC.

Submissão: 11-4-2017

Decisão editorial: 25-9-2018 


\section{Introdução}

Na contemporaneidade, refletir a respeito da cidadania implica um amplo debate sobre como o cidadão utiliza a tecnologia para participar da vida política. No Brasil, ainda com alto índice de desigualdade social, $48 \%$ da população utiliza a internet para consumir ou trocar informações (BRASIL, 2014), e esse novo comportamento está modificando as formas de organização e participação social, dando novo ritmo à política, cujas atividades clássicas estão desaparecendo para dar espaço a "[...] novas formas micropolíticas de ação" (LEMOS, 2005, p. 15).

A fim de discutir esses modelos citados pelo pesquisador, este artigo se propõe a analisar como os deputados federais do Grande ABC eleitos em 2014 se adaptaram ao uso do Facebook naquela campanha eleitoral, definindo o tipo de presença social' desses políticos na mídia. Como consequência, identificar se houve o ato inovar, ou seja, se os sujeitos modificaram suas práticas de comunicação a partir do uso de uma ferramenta tecnológica.

A teoria discute como as mídias interferem na sensação de presença de um sujeito, nesse caso, no ambiente virtual. Trata sobre a sensação de estar presente, mesmo distante fisicamente, sem notar a mediação. 
O ensaio está direcionado ao Grande $A B C$ devido às características da região, que mantém um modelo político-econômico focado no regionalismo, mas que sofre influências diretas de São Paulo no aspecto comunicacional, pois está submetido às mesmas mídias de massa da capital. Ao regionalizar o debate, esta investigação ilustra como os representantes regionais estão utilizando as novas mídias - em especial - Facebook - para moderar discussões sobre políticas públicas de interesse nacional.

Considerando que a população tende a caminhar para modelos de organização e participação pautados no uso das mídias sociais (PERUZZO, 2008), o texto traz resultados concretos a respeito de como os parlamentares que representam o Grande ABC no Congresso Nacional constituem um modelo contemporâneo de comunicação na sociedade em rede (CASTELLS, 1999).

\section{Comunicação política na Cibercultura}

Estudos recentes a respeito da comunicação política versam sobre o uso das mídias sociais no processo de interação entre políticos e eleitores, especialmente no país, considerando que $92 \%$ dos cidadãos conectados utilizam alguma mídia social para se relacionar diariamente (BRASIL, 2014). Concordando com Lemos (2005), é possível observar que as práticas sociais estão se reconfigurando a partir da popularização da tecnologia móvel ou nômade. Isso significa que as novas tecnologias passaram a ser exploradas estrategicamente por públicos diversos, sobretudo no campo político, seja na oferta ou na busca por informações no mundo virtual. 
A palavra virtual neste ensaio segue o sentido definido por Lévy (2000) como a existência em potencial, não em ato. Trata-se de algo ou alguém que existe sem estar presente em um espaço físico. "Um mundo virtual, no sentido amplo, é universo de possíveis, calculáveis a partir de um modelo digital. Ao interagir com o mundo virtual, os usuários o exploram e o atualizam simultaneamente" (LÉVY, 2000, p. 75).

Nesse universo, computadores e redes garantem a infraestrutura necessária para se formar um espaço onde as pessoas se comunicam em tempo real, mesmo quando estão distantes. Na avaliação do autor, o ambiente virtual encoraja "[...] um estilo de relacionamento quase independente dos lugares geográficos (telecomunicação, telepresença) e da coincidência dos tempos (comunicação assíncrona)" (LÉVY, 2000, p. 49). Na cibercultura, a comunicação ganha nova forma, possível por meio das redes digitais interativas, mesmo sem a presença física de dois ou mais sujeitos.

Assumindo que as fronteiras da comunicação e informação são cada vez menores, interessa neste artigo observar a comunicação política, que, no Brasil,

[...] atravessou a tradição oral (do descobrimento ao século XXI), os impressos (jornais e revistas, a partir de 1882), a chegada do rádio (ano 1922), a chegada da televisão (1950) e, por fim, os novos impactos sobre a atividade com a chegada da Internet (1990) (QUEIROZ, 2015, p. 3).

Esta discussão foca a última fase da comunicação política, refletindo com maior profundidade sobre a influência da internet na relação comunicacional imediata entre políticos e eleitores, por meio de um canal onde é possível transmitir textos, imagens, víde- 
os e, mais do que isso, é propício para a interação entre representantes públicos e população conectada, seja na campanha eleitoral ou na manutenção de mandatos.

Segundo Queiroz (2015), o advento da internet e os novos hábitos da sociedade com relação ao uso da ferramenta tecnológica aproximaram o cidadão dos governos, permitindo que a sociedade opine na construção de políticas públicas. "Mas ainda não é uma ação plenamente aceita por partidos e candidatos" (QUEIROZ, 2015, p. 10).

O autor observa a resistência da "velha" classe política, que está submetida a cobranças públicas mais agressivas de uma sociedade jovem e conectada, que domina as ferramentas digitais e que presenciou a campanha eleitoral virtual bem-sucedida do primeiro presidente negro dos Estados Unidos - Barack Obama (2008-2016), que foi eleito após adotar importantes estratégias na internet, como a comunicação com segmentos específicos da sociedade e a arrecadação de recursos financeiros para a campanha por meio de doações virtuais (QUEIROZ, 2015, p. 10).

No Brasil, o uso de mídias sociais na comunicação política começou em 2006, quando o Orkut era considerado a rede social digital mais popular do país. Naquele ano, "[...] constatou-se pela primeira vez o uso de sites de redes sociais nas campanhas ao pleito majoritário, disputado entre Geraldo Alckmin (PSDB) e Lula (PT)" (PENTEADO et al., 2016, p. 279). Os autores lembram que em 2009, após a legislação brasileira normatizar o uso da internet para a arrecadação e como ferramenta comunicacional, as campanhas digitais foram consolidadas (PENTEADO et al., 2016, p. 280). 
Segundo os pesquisadores, a partir de 2010 a comunicação política brasileira ganhou nova dinâmica. À ocasião, os principais candidatos à presidência (Dilma Rousseff - PT, José Serra - PSDB e Marina Silva - ex-PV) oficializaram suas campanhas digitais com profissionais que administravam as respectivas páginas no Facebook, perfis no Twitter e canais no YouTube. "Esse pleito foi pioneiro na realização de modernas cibercampanhas. [...] verificou-se a importância dos sites de redes sociais na aproximação dos políticos com os eleitores" (PENTEADO et al., 2016, p. 280-281).

Ao analisarem a campanha eleitoral de 2012, afirmam que a falta de habilidade para lidar com o Facebook como uma ferramenta de comunicação estratégica levou os candidatos a usarem a mídia "[...] mais como um painel expositor do que um espaço de debate político que estimula o engajamento cívico" (PENTEADO et al., 2016, p. 282). Queiroz segue linha mais crítica ao ponderar que a comunicação política virtual no país, apesar de "ágil e barata", ainda é "incipiente e improvisada" (QUEIROZ, 2015, p. 15).

Considerando os diferentes posicionamentos a respeito do potencial da internet - e por consequência das mídias sociais - na comunicação política, importa observar como os candidatos estão se apropriando desse meio em campanhas eleitorais. Essa é a reflexão proposta a seguir, ao se debater a importância do Facebook no processo eleitoral mais acirrado da história do Brasil.

\section{protagonismo do Facebook na eleição de 2014}

Fundada em 2004, pelo empresário Mark Zuckerberg, o Facebook figura como a maior rede social 
digital do mundo. A organização, com sede na Califórnia, ałua com 15.724 funcionários e tem 1,79 bilhão de usuários ativos, a maioria (84,9\%) fora dos Estados Unidos e do Canadá (FACEBOOK, 2016). ${ }^{2}$ Em sua página oficial, a empresa apresenta a missão de "[...] dar às pessoas o poder de compartilhar e tornar o mundo mais aberto e conectado" (FACEBOOK, 2016c).

No Brasil, o Facebook ocupa o primeiro lugar no ranking das mídias sociais mais acessadas, com $83 \%$ de adesão dos internautas (BRASIL, 2014). A nação está em terceiro lugar em número de usuários no mundo, com $7 \%$ da fatia de adeptos, ficando atrás dos líderes Estados Unidos e Índia. Em 2016, a rede de relacionamento estava inserida no cotidiano de 85,6 milhões e as projeções indicam que o número de usuários da mídia no país deve chegar a 107,5 milhões em 2021 (STATISTA, 2016).

Essa presença massiva no Facebook refletiu no processo eleitoral de 2014. Naquele contexto, a disputa polarizada entre os candidatos Dilma Rousseff (PT), reeleita no segundo turno com $51,6 \%$ dos votos válidos, e Aécio Neves (PSDB), que obteve 48,35\% (TSE, 2015), proporcionou o maior número de interações na rede social virtual em todo o mundo, caracterizando aquelas campanhas eleitorais majoritárias como "cibercampanhas" (PENTEADO et al., 2016).

É nítido o protagonismo do Facebook, sobretudo no processo de participação social, dando aos políticos a oportunidade de interagir com os eleitores conectados. Recuero (2014, p. 115) explica que a mídia social é uma ferramenta apropriada para construir um espaço social no cotidiano de personagens

2 Dados divulgados pela empresa com atualizações em 30 de setembro de 2016. 
- neste ensaio, personagens são figuras políticas que se apropriam do meio para propagar seus discursos.

Em linha com a reflexão da autora, é possível argumentar que o Facebook é uma mídia estratégica a candidatos com baixa - ou nenhuma - presença na grande mídia, ${ }^{3}$ caso dos políticos do Grande ABC, que amargam o fato de a região não ter programação regional na TV aberta. Mais uma razão para se observar como esses sujeitos utilizam a mídia social mais popular do Brasil em suas campanhas eleitorais.

\section{A presença social como perspectiva teórica}

O conceito de presença - seja física (face a face) ou virtual (mediado por alguma tecnologia digital) - tem motivado discussões teóricas fragmentadas a respeito de como uma pessoa é percebida como real em uma comunicação mediada. Em um sentido amplo, Lombard e Ditton (1997) sugerem que qualquer experiência é mediada, mas essa mediação não é obrigatoriamente notada. A ilusão de não mediação pode ocorrer de duas formas: 1) quando o meio parece invisível, com pessoas compartilhando o mesmo ambiente; 2) a forma (ou o meio) pode aparecer e ser transformada em algo que não seja uma forma, mas uma "entidade social".

Considerando que presença é uma interação mediada, mesmo quando há uma ilusão de não mediação, os pesquisadores pressupõem que "[...] não há fronteira para que os usuários percebam se mudaram para o outro lado, que os objetos (ou pessoas) do outro lado entraram seu ambiente imediato, ou que eles

3 Termo adotado no Brasil para mencionar os principais e tradicionais veículos de comunicação (emissoras de TV e rádio, jornais e revistas). 
estão compartilhando um ambiente real ou artificial" (LOMBARD; DITTON, 1997, p. 1). Esse conceito tem relação direta com o uso da tecnologia como um meio não artificial, conforme definem os autores. Assim, os usuários são capazes de interagir com um meio.

Neste artigo, interessa debater justamente o conceito da presença social, que emergiu na década de 1970, e trata da influência das mídias na sensação de presença. Justificando a aplicação da teoria nesta pesquisa, vale esclarecer que, a partir da década de 1980, pesquisadores passaram a abordar como a presença social ocorre em uma comunicação mediada por computadores. Com a popularização da internet, a partir dos anos 2000, os estudos se voltaram para a presença social em ambientes virtuais sociais, como fóruns de ensino a distância.

Nesse contexto, cabe abordar as considerações de Lowenthal (2009) sobre um cenário influenciado pela ascensão da internet, que modificou as formas de relacionamento ao permitir que a sociedade interaja utilizando a ferramenta como meio de comunicação principal. Para o pesquisador, as novas práticas podem significar que as pessoas estão abandonando a presença física, dando espaço à presença social.

Gunawardena (1995, p. 151) explica que presença social é a forma como uma pessoa percebe a própria presença e entende a outra como "real" em relações mediadas por computadores. Segundo a autora, essa percepção tem maior importância do que o meio de comunicação que está sendo usado para promover tal interação.

Por sua vez, Walther (1992) sugere que, no ambiente virtual, as pessoas interagem mais porque sentem maior liberdade para discursar, sem a presença 
física, estabelecendo uma imagem social positiva para atrair a atenção para si. Assim, os receptores podem criar uma imagem idealizada de seus interlocutores. Desse modo, a teoria tem relação direta com este trabalho, pois indica possível supervalorização de textos e imagens de personagens (políticos ou não) presentes no mundo virtual.

A noção de presença social neste artigo considera o modelo sugerido por Rourke et al. (2001). Para analisar o nível de presença social nas mensagens postadas em fóruns virtuais de ensino, considerados espaços sociais, os autores apresentaram as três categorias adaptadas no Quadro 1.

Quadro 1 - Categorias para verificação de presença social.

\begin{tabular}{|l|l|}
\hline Categorias & Indicadores \\
\hline Afetiva & $\begin{array}{l}\text { - Expressão de emoções e sentimentos. } \\
\text { - Uso do humor. } \\
\text { - Autorrevelação do participante. }\end{array}$ \\
\hline Interativa & $\begin{array}{l}\text { - Continuação de um discurso. } \\
\text { - Citação das mensagens de outros. }\end{array}$ \\
& $\begin{array}{l}\text { - Referência explícita a outras } \\
\text { - } \text { Fensagens. }\end{array}$ \\
& $\begin{array}{l}\text { - Expressões de apreciação, } \\
\text { concordância com posts de outros. }\end{array}$ \\
\hline Coesiva & $\begin{array}{l}\text { Vocativos. } \\
\text { - Pronomes inclusivos referir-se ao } \\
\end{array}$ \\
& grupo (nós, nosso). \\
& Expressões fáticas, saudações, \\
& cumprimentos, despedidas. \\
\hline
\end{tabular}

Fonte: Adaptado de Rourke et al., 2001. 
O modelo de Rourke et al. (2001) propõe uma análise objetiva focada no conteúdo de textos e imagens veiculadas em espaços sociais virtuais, podendo ser adaptado a esta pesquisa. Ao sustentarem uma análise ancorada no fluxo comunicacional de pessoas no espaço virtual, as categorias dos autores são adaptáveis, visto que se pretende observar como os dois deputados federais do Grande ABC se projetaram socialmente em um ambiente virtual como "reais" (GUNAWARDENA, 1995).

\section{Delimitação da pesquisa e procedimentos metodológicos}

Levando em consideração a questão da regionalidade, é preciso esclarecer que este ensaio está delimitado ao Grande ABC Paulista, localizado na Região Metropolitana de São Paulo, entre o Porto de Santos e a capital do Estado. Composta por sete cidades Santo André, São Bernardo do Campo, São Caetano do Sul, Diadema, Mauá, Ribeirão Pires e Rio Grande da Serra -, a região tem extensão territorial de 828.702 $\mathrm{km}^{2}$, população estimada em 2.736.683 habitantes e Produto Interno Bruto (PIB) que representa R\$ 120,1 bilhões (IBGE, 2015).

Caracterizada como berço industrial a partir de 1950, a região passa por adaptações desde a última década. Em linhas gerais, o Grande ABC tenta reencontrar uma nova vocação a partir da ideia do regionalismo, em parte prejudicada devido à proximidade com São Paulo. Vale reforçar que a região não tem um sistema de comunicação bem estruturado, o que dificulta a identidade da população com lideranças políticas regionais (SANTOS et al., 2005).

De certo modo, essa fragilidade pode ter refletido no resultado eleitoral de 2014, quando os morado- 
res ajudaram a eleger candidatos de outras cidades com forte presença na televisão aberta. Naquela eleição, a região perdeu metade da representação em Brasília ao eleger apenas dois deputados federais, ambos de São Bernardo: Alex Manente (PPS), eleito pela primeira vez com 164.760 votos; e Vicente Paulo da Silva, o Vicentinho (PT), sendo o único deputado federal do Grande $A B C$ reeleito, ao quarto mandato, com 89.001 adesões (ELEIÇÕES 2014, 2016).

Cabe elucidar que, para a análise proposta, optou-se por uma pesquisa de cunho qualitativo. Tratase de um estudo de caso de "dois casos" (YIN, 2015), tendo como sujeitos os dois deputados federais. A escolha do corpus considerou o fato de os dois utilizarem o Facebook como ferramenta de comunicação digital naquela campanha - suas fanpages estão ativas desde 2012: Alex Manente acumula 38.565 fãs, Vicentinho, 95.461.4 Com apenas dois personagens, foi possível realizar um diagnóstico detalhado aplicando a teoria da presença social para identificar como cada um deles se apresentou como figuras reais naquele ambiente virtual social.

A coleta de dados respeitou: a) pesquisa documental das fanpages desses parlamentares à época da campanha eleitoral (GIL, 1999); (b) entrevistas abertas, não diretivas (HOFFMANN, 2009), com os deputados, os jornalistas responsáveis pelo conteúdo das fanpages (Fernando Trindade e Soraya Paladini) e três especialistas em comunicação política com estudos voltados à América Latina, ao Brasil e ao Grande ABC, são eles: os professores Francisco Sierra Caballero, Roberto Gondo Macedo e Adolpho Carlos Françoso Queiroz.

4 Dados atualizados em 5 de abril de 2017. 
Com base na análise de conteúdo proposta por Bardin (2004), duas técnicas foram seguidas no percurso metodológico: 1) a análise categorial dos dados extraídos das fanpages; 2) a análise de enunciação das entrevistas. A primeira foi embasada nas três categorias sugeridas por Rourke et al. (2001) aqui apresentadas.

A análise segue o recorte temporal dos 90 dias do primeiro turno - entre 6 de julho e 5 de outubro. Optou-se pela semana construída ou artificial (RIFFE; AUST; LACY, 1993; BAUER; GASKELL, 2008) para consolidar uma amostragem sem desvios do vasto conteúdo veiculado nas fanpages desses políticos.

Importante destacar que o material coletado contém imagens e textos veiculados pelas respectivas equipes de comunicação, bem como, comentários de internautas com acesso à mídia social desses políticos. Todas as mensagens, incluindo fotografias e artes da campanha eleitoral, foram tratadas com o suporte do software Atlas TI. ${ }^{5}$ Assim, seguindo os preceitos de Bardin (2004), foi possível objetivar a codificação e categorização do conteúdo da semana construída.

\section{Resultados: a presença social dos Deputados Federais no Facebook}

Ao se apropriar das categorias de Rourke et al., este trabalho inova ao ilustrar o caso dos dois deputados federais do Grande ABC eleitos no ano em que o Brasil bateu o recorde mundial de interações no Facebook sobre o tema eleições. A análise de conteúdo dos posts, vinculada ao objetivo geral desta

5 Desenvolvido para análises qualitativas em alta escala, a plataforma identifica palavras transcritas em documentos ou imagens e cria códigos com base em categorias definidas pelo pesquisador. 
pesquisa, indica que a presença social de ambos os parlamentares no Facebook é coesiva.

A categorização revela que Alex Manente tem presença social genuinamente coesiva, a categoria representa $97 \%$ de suas mensagens. Apenas $3 \%$, ou uma postagem se enquadra na categoria afetiva. Não se observou interatividade (Gráfico 1).

Gráfico 1 - Presença social de Alex Manente no Facebook.

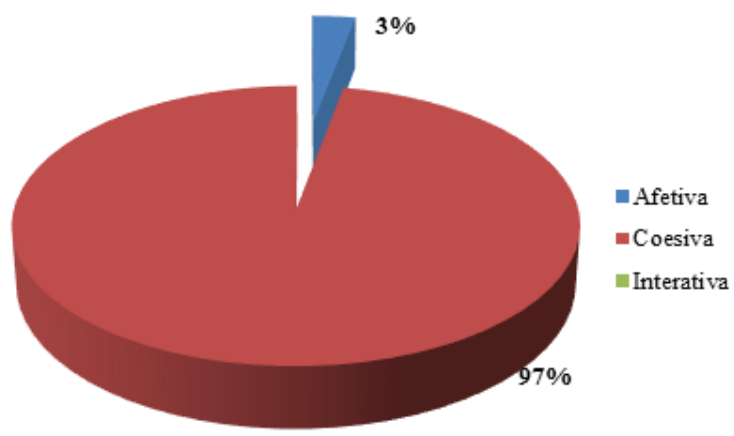

Resultados extraídos do Atlas TI.

Vicentinho apresenta $86 \%$ de coesão em suas mensagens; $14 \%$ representam afetividade e, apesar de nenhuma postagem se encaixar na categoria interativa (Gráfico 2), o parlamentar tem uma visão diferenciada sobre a importância da ferramenta na comunicação, reforçando o papel da mídia na abertura de diálogo entre a sociedade e representantes políticos. Nesse sentido, os dois parlamentares se diferenciam, já que Alex Manente não acredita no potencial do Facebook para dialogar com os cidadãos (MANENTE, 2016; SILVA, 2016). ${ }^{6}$

6 Entrevistas concedidas pelos deputados federais Alex Manente [11/08/2016] e Vicente Paulo da Silva, Vicentinho [15/08/2016]. São Bernardo do Campo-SP, 2016. 
Gráfico 2 - Presença social de Vicentinho no Facebook.

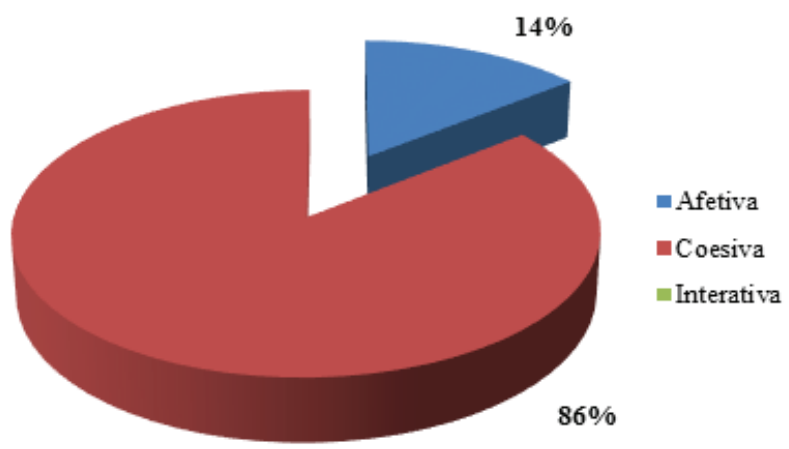

Resultados extraídos do Atlas TI.

A principal semelhança entre os dois casos é a proximidade com a população e com lideranças, sejam elas políticas ou populares (atores da comunidade), de representatividade local/regional e nacional. Outro apontamento marcante nas mensagens analisadas é que esses sujeitos se esforçam para demonstrar compromisso com a sociedade, seja quem for o cidadão, é tratado como parte de um grupo nos textos veiculados. Em outros casos, a mensagem é puramente social, usando vocativos para se referir a outros participantes e o pronome "nosso/nós" em imagens ou mensagens com mais de duas pessoas, o que sugere aproximação de um grupo (ROURKE e† al., 2001).

O exemplo mais recorrente de coesão na fanpage de Alex Manente é observado na Figura 1, com data de 30 de julho. A maioria dos posts segue o mesmo: o então candidato em alguma reunião, recebendo a atenção da população enquanto discur- 
sa. Os textos também seguem linguagem simples, em muitos casos, com o uso de vocativos - explorando o recurso marcação do Facebook - e, como regra, o uso de pronomes inclusivos (nós, nosso) para se referir ao grupo de pessoas presente na imagem.

Figura 1 - Exemplo de coesão 3 - Alex Manente.
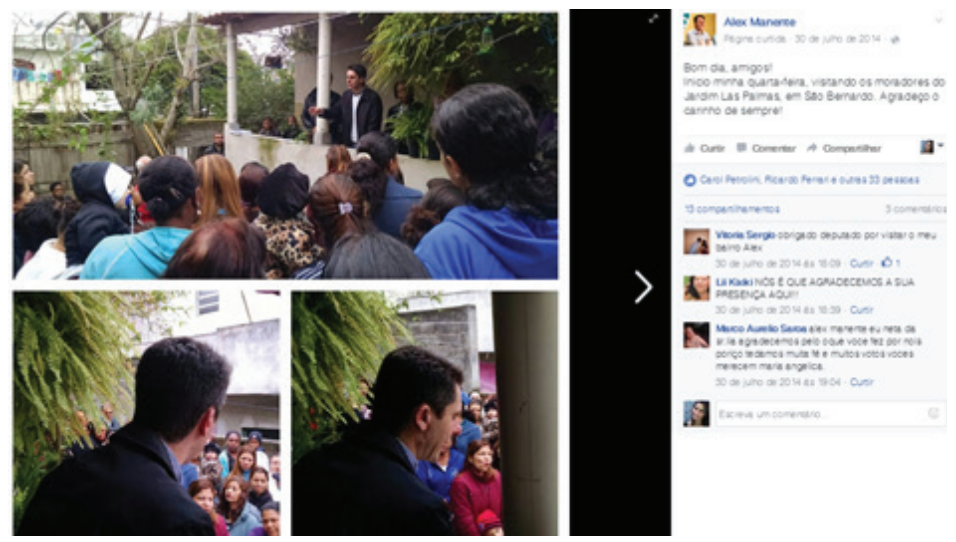

Fonte: Facebook, $2016 a$.

Outra característica das mensagens coesivas veiculadas na página do parlamentar é o cumprimento e o agradecimento. Na Figura 1, é possível observar que o texto sugere que o leitor é próximo, um "amigo", e que o deputado faz parte daquele grupo que, em suas palavras, sempre o recebe com carinho. A coesão, nesse caso, se faz presente não apenas na tentativa de demonstrar proximidade, mas, sobretudo, quando o texto reforça comprometimento do agente. A frase "[sic] Inicio minha quarta-feira, visitando os moradores do Jardim Las Palmas, em São Bernardo" sugere que o candidato assume um compromisso com os moradores daquele bairro. 
Seguindo as categorias de presença social de Rourke et al. (2001), é possível observar a coesão nas postagens de Vicentinho no exemplo recortado na Figura 2. As mensagens veiculadas no Facebook do deputado federal usam frases curtas ou nenhuma frase. Por vezes, o texto está incluso na própria imagem manipulada com arte da campanha eleitoral. No primeiro exemplo, veiculado no dia 2 de outubro, a coesão aparece na frase "É do povo. É da gente", reforçando a mensagem do parlamentar como um candidato que pertence ao povo.

Figura 2 - Exemplo de coesão 1 - Vicentinho.

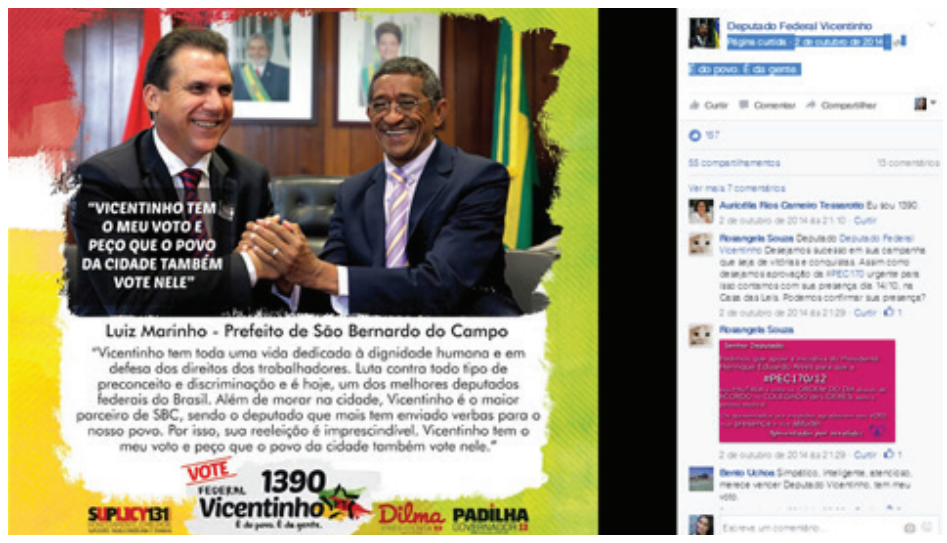

Fonte: Facebook, $2016 \mathrm{~b}$.

Ao utilizar a imagem do prefeito de São Bernardo à época, Luiz Marinho, a peça publicitária induz o internauta a confiar na parceria do então candidato com a principal liderança política de sua cidade. Sugere-se que ele pertence a um grupo político apoiado pelo prefeito, que usa a frase "Vicentinho tem meu voto e peço que o povo da cidade tam- 
bém vote nele", demonstrando união e confirmando a mensagem como coesiva.

O pesquisador Sierra Caballero $(2016)^{7}$ indica que as mídias sociais se constroem por meio de vínculos, relações. Tais vínculos parecem mais evidentes nas postagens do deputado federal Vicentinho. Uma das mensagens afetivas da página do parlamentar está ilustrada na Figura 3. De modo diferente da coesão, que usa vocativos para se referir a um participante como o nome da pessoa -, a mensagem dá o sentido de intimidade entre os personagens, pela forma como se abraçam, parecendo transmitir emoção.

Figura 3 - Exemplo de afetividade 1 - Vicentinho.

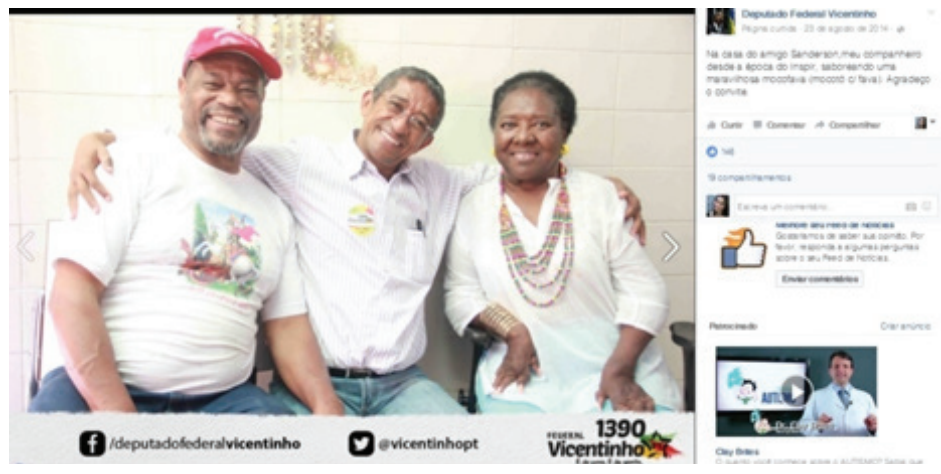

Fonte: Facebook, 2016b.

Ademais, a frase usada na descrição da imagem sugere algum envolvimento: "Na casa do amigo Sanderson, meu companheiro desde a época do Inspir, saboreando uma maravilhosa mocofava (mocotó c/ fava). Agradeço o convite". Como se pode observar, as características são típicas de uma mensagem afe-

7 Entrevista concedida por Francisco Sierra Caballero [5/09/2016]. São Bernardo do Campo-SP, 2016. 
tiva, confirmadas no discurso de Vicentinho. "Faço questão de colocar [nas mídias sociais] um amigo meu de longa data, ou quando vou ao campo, ou outro lugar" (SILVA, 2016). A postura reforça uma inclinação de presença social afetiva, como aponta o Gráfico 2.

Rourke et al. (2001) destacam que a demonstração de emoção, humor e sentimentos é comum em mensagens afetivas. Assim, ao se analisar a postagem veiculada na fanpage de Alex Manente no dia 5 de outubro, após o resultado da eleição (Figura 4), é possível notar o humor - o parlamentar fora eleito com a maior quantidade de votos do partido no país e obteve a maior votação da região do Grande ABC.

Figura 4 - Exemplo de afetividade - Alex Manente.
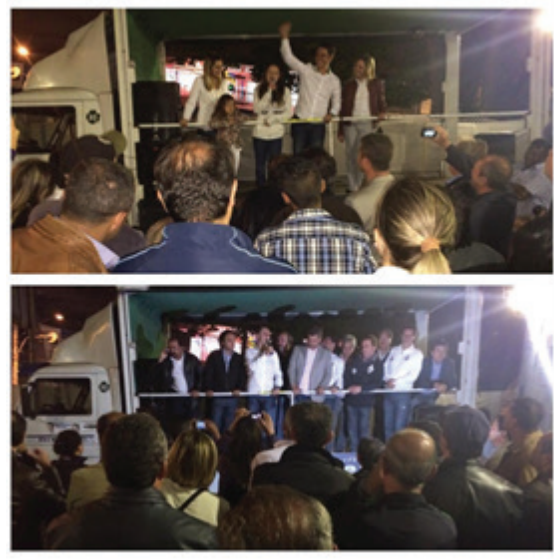

Fonte: Facebook, $2016 a$.

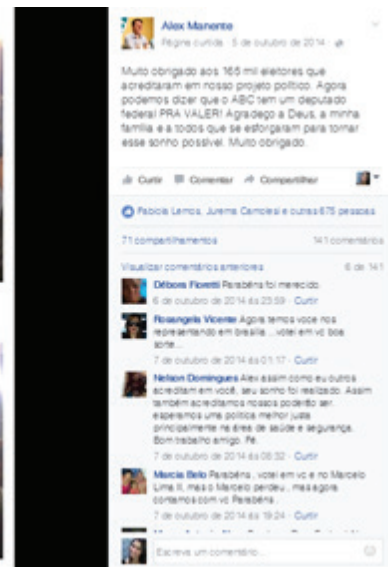

Apesar de usar o pronome "nosso", a mensagem é predominantemente afetiva - a única de toda a amostragem -, pois traz a frase "Muito obrigado aos 165 mil eleitores que acreditaram em nosso projeto político. Agora podemos dizer que o ABC tem um 
deputado federal [sic] PRA VALER!" no contexto de uma fotografia do deputado ao lado da família, em um palco, comemorando a vitória. A mensagem é atípica, traz um texto com mais detalhes, em tom afetivo, de modo diferente do convencional usado pela equipe no dia a dia da campanha.

Ao se analisar a frase que complementa o post, "Agradeço a Deus, a minha família e a todos que se esforçaram para tornar esse sonho possível. Muito obrigado", é possível observar o sentimento de gratidão, categorizando a mensagem como afetiva. Independentemente de ter sido produzida pelo profissional que abastecia a mídia, e não pelo próprio parlamentar, a mensagem conota emoção. Nesse exemplo, pode-se sugerir outro indicador presente na categoria afetiva: a autorrevelação do participante. Entretanto, em entrevista a este trabalho, o deputado federal afirmou que mensagens afetivas constroem um tipo de imagem política que ele não pretende se vincular.

\section{A falta de interatividade dos candidatos com os eleitores conectados}

A análise dos posts selecionados na amostragem foi criteriosa e permitiu identificar que não houve quaisquer trocas interativas entre os parlamentares (ou suas equipes) e os internautas no espaço comentários da mídia social. Na visão de Manente, essa troca não ocorreu porque o Facebook, no contexto político, ainda é uma ferramenta para facilitar pesquisas, não para dialogar. "A interação é uma ferramenta que as pessoas deveriam usar mais com os seus representantes. Eu acho que tem aumentado, mas ainda é pouco. Talvez porque as pessoas não 
demonstrem um interesse em procurar a página de alguém" (MANENTE, 2016).

Por sua vez, Vicentinho é favorável à interação com os internautas, observado de forma muito sutil em algumas mensagens veiculadas durante a campanha eleitoral. Para esclarecer em que momento há uma tentativa de interação, importa sinalizar que algumas das postagens apresentavam o trabalho do deputado federal, endereçando perguntas a trabaIhadores por categorias. Fazer perguntas é um indicativo de presença social interativa (ROURKE et al., 2001), no entanto, as mensagens não foram categorizadas como tal por não seguirem preceitos básicos de uma interação, tais quais a continuação de um discurso ou a referência a mensagens de outros.

Fato que não configura sua presença social no Facebook como interativa naquele período é a falta de respostas aos internautas que tentaram interagir com o deputado nos comentários. No período analisado, nenhum questionamento de internautas no campo comentários foi respondido. Contudo, é preciso ressaltar que as interações podem ocorrer em ambiente privado - o inbox -, dentro da própria ferramenta, e que pode ser acessado somente pelos administradores da fanpage.

Por considerar as mídias sociais "instrumentos revolucionários, democráticos e necessários para a comunicação" com a população conectada, Vicentinho argumenta que está aberto a discussões nesse ambiente, onde se pode captar o sentimento das pessoas, segundo o deputado federal. "Eles transmitem preconceito, transmitem ódio. Eu acho que essa liberdade dá margem também para isso. Mas também há oportunidade de fazer as pessoas 
se conscientizarem" (SILVA, 2016). A argumentação do parlamentar ilustra a sua tentativa de presença social interativa.

Queiroz vê como uma prática natural a falta de interação entre políticos e seus seguidores em redes sociais virtuais. "Essas pessoas [públicas] vão passar meia hora ali. Às vezes, vão deixar assessores tocarem [...] e eles não têm essa relação de afeto que trouxe os dois a esse momento na vida pública" (QUEIROZ, 2016). ${ }^{8}$ A observação do pesquisador sugere a dificuldade de se construir relações com pessoas públicas na mídia social, já que nem sempre os agentes administram seus perfis pessoais e fanpages.

Para Sierra Caballero, em países democráticos não há como impedir que o público, sobretudo o jovem, interaja utilizando as novas tecnologias como recurso de comunicação. "[...] Os agentes constroem um imaginário político, especialmente em classes médias e altas, com maior nível de capital cultural cognitivo, mais pelo acesso às redes sociais digitais do que por meios mainstream, por sistema de rádio e televisão" (SIERRA CABALLERO, 2016).

Esse comportamento interativo, segundo o estudioso, estaria vinculado à própria maturidade de uma geração nascida na era da conexão, que recorre primeiramente à internet para obter informações, portanto, tem familiaridade com esse ambiente e constrói seus discursos utilizando linguagem específica do mundo on-line. "Todo o seu imaginário é construído através das redes sociais [virtuais]. Assim, por trás de ciências políticas, de campanha, dos partidos, estão surgindo grupos que eles falam também da política,

8 Entrevista concedida por Adolpho Carlos Françoso Queiroz [28/10/2016]. São Paulo-SP, 2016. 
do público, e vão construindo seu imaginário nesse espaço" (SIERRA CABALLERO, 2016).

Concordando com o argumento, Queiroz reforça que as mídias sociais caminham para ocupar um papel fundamental no processo político. Para o pesquisador, esse cenário deve ser visível daqui a vinte anos, "[...] quando essa geração que hoje está com 16 chegar aos 40. Porque, quem está com 16 e já está na Internet não lê jornal impresso, não lê revista impressa, não ouve rádio, pouco vê a TV aberta nas condições que ela tem hoje" (QUEIROZ, 2016).

\section{Considerações finais}

Para além do debate sobre a presença social de políticos no Facebook, este ensaio sugere que o uso da mídia nas campanhas dos dois deputados federais do Grande $A B C$ se trata de uma tática integrada à necessidade de cada parlamentar. Assim, suas campanhas não se enquadram no conceito de "cibercampanhas", pois não se observa estratégias voltadas especificamente para o ambiente social virtual. Em nenhum post da amostra analisada há a clara intenção de formatação de um discurso ou aproximação desses parlamentares com seus seguidores por meio da mídia social, já que não houve interatividade no período eleitoral.

Essa nítida ausência de interação com os eleitores conectados, aliás, cabe dentro da hipótese de como esses personagens políticos subestimam o Facebook como uma ferramenta de comunicação estratégica, mesmo em uma região com mídia local tão fragilizada. Ao se discutir essa postura de não interagir, a análise sugere a possível falta de habilidades técnicas desses candidatos, ou suas equipes, 
para lidar com uma tecnologia que permite o diálogo contínuo, em tempo real, com os internautas.

Desse modo, suas fanpages foram transformadas em espécies de murais de fotografias e frases de efeito, minimizando o potencial da mídia no processo comunicacional contemporâneo. Alex Manente assumiu que não teve a pretensão de explorar o Facebook estrategicamente, reforçando a presença social coesiva, conforme se constatou; Vicentinho, apesar dos argumentos sobre a profissionalização da equipe de comunicação digital, não seguiu as premissas de uma presença social interativa.

Esta análise indica que as campanhas eleitorais desses deputados federais passaram pelo processo de convergência digital em 2014, promovendo a integração de mídias no ambiente virtual. Observa-se que os materiais publicitários criados para circular nas ruas, assim como os vídeos pensados para inserções na TV ou no YouTube, foram disponibilizados no Facebook. Entretanto, em nenhum dos casos se apostou em uma linguagem específica para esse tipo de mídia e/ou público.

\section{Referências}

BARDIN, Laurence. Análise de Conteúdo, 3. ed. Lisboa, Portugal: Edições 70, 2004.

BAUER, Martin W.; GASKELL, George. Pesquisa qualitativa com texto, imagem e som: um manual prático, 7 ed., Petrópolis, RJ: Vozes, 2008.

BRASIL. Presidência da República. Secretaria de Comunicação Social. Pesquisa Brasileira de Mídia 2015: hábitos de consumo de mídia pela população brasileira. Brasília: Secom, 2014.

CASTELLS, Manuel. A Sociedade em Rede. A era da informação: economia, sociedade e cultura, v. 1, 6. ed. São Paulo: Paz e Terra, 1999. 
ELEIÇÕES 2014. Resultados para deputado federal (1. turno), 2015. Disponível em: http://www.eleicoes2014.com.br/candidatos-deputado-federal/. Último acesso em: 28 dez. 2016.

FACEBOOK. Newsroom. Company Info, 2016. Disponível em: http:// newsroom.fb.com/company-info/. Acesso em: 1. dez. 2016.

Fanpage Alex Manente, 2016. Disponível em: https://www. facebook.com/alexmanentesbc/?fref=ts. Último acesso em: 11 nov. $2016 a$.

Fanpage Deputado Federal Vicentinho, 2016. Disponível em: https://www.facebook.com/DeputadoFederalVicentinho/? fref=ts. último acesso em: 11 nov. $2016 \mathrm{~b}$.

. Homepage Facebook Careers, 2016. Disponível em: https:// www.facebook.com/pg/ facebookcareers/about/?ref=page_internal. Acesso em: $1^{\circ}$. de dez. $2016 c$.

GIL, Antonio Carlos. Métodos e Técnicas de Pesquisa Social. São Paulo: Atlas, 1999.

GUNAWARDENA, Charlotte N. Social presence theory and implications for interaction and collaborative learning in computer conferences. International journal of educational telecommunications, $v$. 1, n. 2/3, p. 147-166, 1995. Disponível em: https://www.learntechlib. org/p/15156. Acesso em: 13 nov. 2016.

HOFFMANN, Maria Vitória; OLIVEIRA, Isabel Cristina Santos. Entrevista não-diretiva: uma possibilidade de abordagem em grupo. RevBrasEnferm, v. 62, n. 6, p. 923-7, 2009. Disponível em: http://www.scielo. br/pdf/reben/v62n6/a21v62n6.pdf.

Acesso em: 15 nov. 2016.

IBGE. Projeção da população do Brasil e das Unidades da Federação, 2015. Disponível em: http://www.ibge.gov.br/apps/populacao/ projecao/index.html. Último acesso em: 2 jan. 2016.

LEMOS, André. Cibercultura e mobilidade: a era da conexão. In: CONGRESSO BRASILEIRO DE CIÊNCIAS DA COMUNICAÇÃO, 28, 2005, Rio de Janeiro. Anais... Rio de Janeiro, 2005.

LÉVY, Pierre. Cibercultura. São Paulo: Editora 34, 2000. 
LOMBARD, M. DITTON, T. At the heart of it all: The concept of presence. Journal of Computer-mediated communication, 1997. Disponível em: http://onlinelibrary.wiley.com/doi/10.1111/j.1083-6101.1997. tb00072.x/full.

Acesso em: 13 nov. 2016.

LOWENTHAL, Patrick R. The Evolution and Influence of Social Presence Theory on Online Learning. Social Computing: Concepts, Methodologies, Tools, and Applications: Concepts, Methodologies, Tools, and Applications, p. 113, 2009.

PENTEADO, Claudio Luis de Camargo; PEREIRA, Natasha Bachini; FIACADORI, Giuliana. O Planalto em disputa no Facebook: Um estudo dos perfis de Dilma Rousseff e Aécio Neves nas eleições de 2014. In: CERVI, Emerson Urizzi; GOULART, Michele Massuchin; CARVALHO, Fernanda Cavassana de (Org.). Internet e eleições no Brasil. Curitiba: CPOP (Grupo de Pesquisa em Comunicação Política e Opinião Pública). E-book versão PDF, p. 275-295, 2016.

PERUZZO, Cicilia M. Krohling. Conceitos de comunicação popular, alternativa e comunitária revisitados. Reelaborações no setor. Palabra Clave, v. 11, n. 2, 2008. Disponível em: http://palabraclave.unisabana.edu.co/index.php/palabraclave/article/ view/1503/1744. Acesso em: 27 set. 2015.

QUEIROZ, Adolpho Carlos Françoso. Das origens e perspectivas sobre o Marketing Político no Brasil. In: Anais do Congresso Corrupção,

Democracia e Dilemas Eleitorais. Rio de Janeiro, 2015. Disponível em: https://drive.google.com/file/d/OB_OzZ5EyOITzcmZhLTh5LTY2Rzg/ view. Acesso em: 5 dez. de 2016.

RECUERO, Raquel. Curtir, compartilhar, comentar: trabalho de face, conversação e redes sociais no Facebook. Verso e Reverso, v. 28, n. 68, p. 117-127, 2014. Disponível em: http://revistas.unisinos.br/index. php/versoereverso/article/view/7323. Acesso em: 18 de nov. 2016.

RIFFE, Daniel; AUST, Charles F.; LACY, Stephen R. The effectiveness of random, consecutive day and constructed week sampling in newspaper content analysis. Journalism \& Mass Communication Quarterly, v. 70, n. 1, 1993.

ROURKE, Liam; ANDERSON, Terry; GARRISON, D. Randy; ARCHER, Walter. Assessing social presence in assynchronous text-based, computer conference. Journal of Distance Education, v. 14, n. 2, 2001. 
SANTOS, Roberto Elísio; LICHT, René Henrique Gotz, GIL; Antonio Carlos. A comunicação regional no contexto da Globalização: uma reflexão sobre a Região do Grande ABC. In: CONGRESSO BRASILEIRO DE CIÊNCIAS DA COMUNICAÇÃO, 28., 2005. Rio de Janeiro. Anais... São Paulo: Intercom, 2005.

STATISTA. Number of Facebook users in Brazil from 2015 to 2021, 2016. Disponível em: https://www.statista.com/statistics/244936/number-offacebook-users-in-brazil/. Acesso em: 1º. dez. 2016.

WALTHER, Joseph B. Interpersonal effects in computer-mediated interaction: relational perspective. In: Communication Research, $v$. 19 , n. 1, 1992, p. 52-90.

YIN, Robert K. Estudo de Caso: Planejamento e Métodos. Porto Alegre: Bookman, 2015.

\section{Arquimedes Pessoni}

ORCID iDhttp://orcid.org/0000-0003-1050-3405

http://orcid.org/0000-0003-1050-3405

Universidade Municipal de São Caetano do Sul

Professor do Programa de Mestrado em Comunicação da Universidade Municipal de São Caetano do Sul (USCS)

pessoni@uscs.edu.br

\section{Rita de Cássia Donato dos Santos}

ORCID iDhttp://orcid.org/0000-0001-8867-6686

http://orcid.org/0000-0001-8867-6686

Mestre em Comunicação da Universidade Municipal de São

Caetano do Sul

Mestre em Comunicação e Inovação pela Universidade Municipal de São Caetano do Sul (USCS) - bolsista CAPES. Possui especialização em Marketing pela Universidade Metodista de São Paulo (UMESP-2010) e graduação em Jornalismo pela USCS (2005) - bolsista CNPq/ pesquisadora do Programa Institucional de Iniciação Científica (2004-2005). Professora nos cursos de Pós-graduação em Comunicação EaD da Metodista e na Graduação em Comunicação do Centro Universitário SantAnna (UniSantAnna). Atua na área de Comunicação Social desde 2004 e tem ampla experiência em jornalismo impresso e virtual, com foco na editoria de Política. Na Comunicação Interna de empresas privadas, desenvolveu ações de endomarketing, auditoria e gestão de mídias digitais. Na Assessoria de Imprensa de órgãos públicos - esferas municipal e estadual -, foi responsável pelo 
planejamento estratégico, relacionamento com a mídia, media training e gerenciamento de crises. Também implementou plano de comunicação em campanhas políticas para os poderes Executivo e Legislativo.

ridonato@gmail.com 